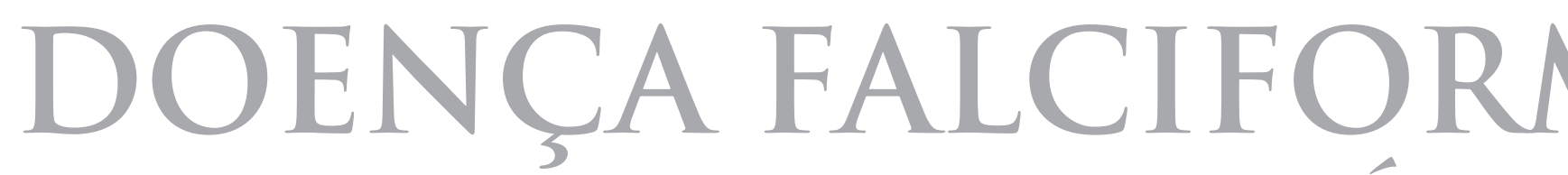
PRECONCEITO LINGUÍST

$$
\text { E SOCIORRACIA }
$$

DESINFORMAÇÃO CO

\title{
DETERMINANTE SOC
}

DA SAUUDE NO ESTADO PARÁ, AMAZÔ 


\section{DOENÇA FALCIFORME, PRECONCEITO LINGUIISTICO E SOCIORRACIAL: A DESINFORMAÇÃO COMO DETERMINANTE SOCIAL DA SAUUDE NO ESTADO DO PARÁ, AMAZÔNIA}




\section{DOENÇA FALCIFORME, PRECONCEITO LINGUÍSTICO E SO- CIORRACIAL: A DESINFORMAÇÃO COMO DETERMINANTE SOCIAL DA SAÚDE NO ESTADO DO PARÁ, AMAZÔNIA}

\section{Resumo}

$\mathrm{O}$ artigo discute o preconceito linguístico e sociorracial vivenciado por pessoas com Doença Falciforme (DF) no Estado do Pará, tanto nos Serviços Públicos e Privados de Saúde como na Escola, na Família e no Trabalho, resultado de uma pesquisa de campo com 45 interlocutores que convivem com o agravo e que recebem inúmeros apelidos (insultos) por causa de sua condição genética. A metodologia foi baseada em pesquisa qualitativa no Centro de Hemoterapia e Hematologia do Estado do Pará - Fundação HEMOPA (2010-2011), após aprovação no Comitê de Ética em Pesquisa do hemocentro, com entrevistas semiestruturadas sobre como é viver com a DF no Pará, estudo etnográfico e levantamento bibliográfico sobre o tema. Objetivou-se classificar o preconceito linguístico e sociorracial vivenciado pelos indivíduos com DF como um Determinante Social da Saúde (DSS), o que torna a situação de saúde e de vida deles um problema a ser enfrentado. Os resultados indicam que 57\% das pessoas entrevistadas já sofreram algum tipo de preconceito - seja linguístico e/ou sociorracial -, sendo que o cotidiano biossocial dos interlocutores com o agravo é considerado como difícil de vivenciar. Conviver com apelidos qualificados pela 'força' da Língua Portuguesa é visto como uma demanda de saúde pública e analisado como um DSS por envolver situações de racismo e intolerância com o Outro, além da desinformação sobre a DF, tanto de quem pratica quanto de quem lida com o preconceito. Desse modo, é de fundamental importância que a DF seja assunto de divulgação entre os órgãos competentes a fim de adquirir maior conhecimento e informações sobre a doença e, assim, obter a melhoria da situação de saúde dos sujeitos com DF no Estado do Pará.

Palavras-chave: Doença Falciforme, Preconceito Linguístico e Sociorracial, Determinantes Sociais da Saúde, Amazônia. 


\title{
SICKLE CELL DISEASE, LINGUISTIC AND SOCIO-RACIAL PRE- JUDICE: DISINFORMATION AS A SOCIAL DETERMINANT OF HEALTH IN THE STATE OF PARÁ, AMAZONIA.
}

\begin{abstract}
This article discusses the linguistic and socio-racial prejudice experienced by people with sickle cell disease (SCD) in the State of Pará, both in Public and Private Health Services as wells as in School, Family and Work, it is the result of a field research with 45 interlocutors who live with the disease and who receive numerous nicknames (insults) because of their genetic condition. The methodology was based on qualitative research at the Hematology and Hemotherapy Center of the State of Pará - HEMOPA Foundation (2010-2011), after approval by the Hemocenter Research Ethics Committee, with semi-structured interviews on how to live with the SCD in Pará, an ethnographic study and a bibliographical review on the subject. The objective was to classify the linguistic and socio-racial prejudice experienced by individuals with SCD as a Social Determinant of Health (DSS), which makes their health and life situation a problem to be faced. The results indicate that $57 \%$ of the people interviewed have already suffered some type of prejudice - whether linguistic and/or socio-racial and that the daily bio social of the interlocutors with the disease is considered as difficult to experience. Living with nicknames qualified by the 'strength' of the Portuguese Language is seen as a requirement of public health and analyzed as a DSS because it involves situations of racism and intolerance with the Other, besides the misinformation about the SCD, both of those who practice and who deal with the prejudice. Thus, it is of fundamental importance that SCD be a matter of dissemination among the competent sectors in order to increase knowledge and information about the disease and, so, to obtain the improvement of the health situation of subjects with SCD in the State of Pará.
\end{abstract}

Keywords: Sickle cell disease, linguistic and socio-racial prejudice, Social Determinants of Health, Amazon. 


\section{ENFERMEDAD DE CÉLULAS FALCIFORMES, PREJUICIO LIN- GÜÍSTICO Y SOCIO-RACIAL: LA DESINFORMACIÓN COMO DETERMINANTE SOCIAL DE LA SALUD EN EL ESTADO DE PARÁ, AMAZONIA.}

\section{Resumen}

El artículo discute el preconcepto lingüístico y socio-racial vivenciado por personas con enfermedad de células falciformes (ECF) en el Estado de Pará, tanto en los servicios públicos y privados de salud como en la Escuela, la Familia y el Trabajo, resultado de una investigación de campo con 45 interlocutores que viven con la enfermedad y que reciben numerosos apodos (insultos) a causa de su condición genética. La metodología se basó en investigación cualitativa en el Centro de Hemoterapia y Hematología del Estado de Pará - Fundación HEMOPA (2010-2011), tras su aprobación por el Comité de Ética en Investigación del Hemocentro, con entrevistas semiestructuradas sobre cómo es la vida con ECF, en Pará, estudio etnográfico y levantamiento bibliográfico sobre el tema. El objetivo del estudio fue clasificar el prejuicio lingüístico y socio-racial vivenciado por las personas con ECF como un Determinante Social de la Salud (DSS), lo que hace que la situación de salud y la vida de ellos sea concebida como un problema a enfrentar. Los resultados indican que el 57\% de las personas entrevistadas sufrieron algún tipo de perjuicio - ya sea lingǘstico y/o socio-racial -, siendo que el cotidiano bio-social de los interlocutores con la enfermedad es considerado como difícil de experimentar. Convivir con apodos calificados por la 'fuerza' de la Lengua Portuguesa es visto como una exigencia de la salud pública y se examina como un DSS para dar lugar a situaciones de racismo e intolerancia con el Otro, además de la desinformación sobre la ECF, tanto de quienes practican como de quienes lidian con el prejuicio. Por lo tanto, es de fundamental importancia que el ECF sea un objeto de divulgación entre los órganos pertinentes, con el fin de adquirir más conocimiento e información sobre la enfermedad y así obtener mejores condiciones de salud en los sujetos con ECF en el Estado de Pará.

Palabras-clave: Enfermedad de Células Falciformes, Perjuicio Lingüístico y Socio-Racial, Determinantes Sociales de la Salud, Estado de Pará, Amazonas. 


\section{DREPANOCYTOSE, PREJUDICE LANGUE ET SOCIO-RACIA- LE : LA DESINFORMATION COMME DETERMINANT SOCIAL DE LA SANTE DANS L'ÉTAT DE PARA, AMAZONIA.}

\section{Résumé}

L'article traite de la discrimination linguistique et socio-raciale vécue par les personnes atteintes de la maladie drépanocytaire (MD) en Pará, les deux services publics et de la santé privée et de l'école, la famille et le travail, résultat d'une recherche sur le terrain avec 45 partenaires qui vivent avec la blessure et recevant de nombreux surnoms (insultes) en raison de leur condition génétique. La méthodologie a été basée sur la recherche qualitative au Centre d'Hématologie et de l'État de Pará Hématologie - Fondation HEMOPA (2010-2011), après approbation par le comité d'éthique de la recherche du centre de sang, avec des interviews semi-structurées sur la vie avec le MD dans le Pará, l'ethnographie et de la littérature sur le sujet. Cette étude visait à classer la discrimination linguistique et socio raciale vécue par les personnes atteintes de la MD comme un Déterminant Social de la Santé (DSS), ce qui rend la situation de la santé et de la vie d'entre eux un problème à relever. Les résultats indiquent que $57 \%$ des personnes interrogées avaient subi une sorte de préjugés - que ce soit linguistique et/ou socio-raciale -, et la bio sociale des interlocuteurs de tous les jours avec le grief est considéré comme difficile à vivre. Vivre avec des surnoms qualifiés la 'force' de la Langue Portugaise est considérée comme une demande de santé publique et examiné comme DSS à impliquer des situations de racisme et de l'intolérance avec l'Autr, qui ont tous deux pratiquent que de ceux qui traitent des préjugés. Ainsi, il est d'une importance fondamentale que le MD est sujet de la divulgation entre les organismes compétents afin d'acquérir plus de connaissances et d'informations sur la maladie et obtenir ainsi un meilleur état de santé des sujets atteints de MD dans l’État de Pará.

Mots-clés: Drépanocytose, Prejudice Langue et Socio-Raciale, Déterminants Sociaux de la Santé, Amazonie.

Endereço da autora para correspondência: Avenida Marquês de Herval, Vila Isabel, 133, entre Enéas Pinheiro e Pirajá, Pedreira, Belém, Pará, Brasil, CEP :66087-730

arianabelem@gmail.com 


\section{INTRODUÇÃO}

O artigo descreve um estudo etnográfico realizado com um grupo de 45 pessoas com Doença Falciforme ${ }^{1}$ (DF) discutindo a situação de conviver com "apelidos" (insultos ou acintes) devido à condição genética dos interlocutores, circunstâncias vivenciadas ao longo de suas vidas e classificadas como preconceito linguístico e sociorracial, ocasião considerada como um Determinante Social da Saúde (DSS) dos sujeitos em questão. O levantamento foi realizado no Centro de Hemoterapia e Hematologia do Pará - Fundação HEMOPA, entre 2010 e 2011, após aprovação no Comitê de Ética e Pesquisa (CEP) do hemocentro, com o propósito de compreender como é viver com DF no Estado do Pará, Amazônia.

De acordo com o dicionário Silveira Bueno (2007: 20 e 73), a palavra "acinte" significa: "s. m. Ação premeditada para desgostar alguém; provocação. adv. por -: de propósito”. Já o vocábulo "apelido" quer dizer: "s. m. Codinome ou sobrenome da família; alcunha; designação particular com conotação de qualidade ou defeito". Desse modo, acintes e apelidos podem ser consideradas expressões que ferem ou maltratam outrem, de modo generalizado.

Desde a origem dos primeiros Homo sapiens, provavelmente no Continente Africano, com o seu magnífico aparelho fonador, que os humanos, em algum momento que não sabemos qual, desenvolveram a linguagem falada, tornando o nosso clado sui generis nesse artifício. A linguagem humana é uma circunstância de processos evolutivos e culturais, portanto, uma característica fundamental não apenas como instrumento de comunicação, mas também de sobrevivência dos grupos, que elegiam estratégias de caça, coleta e forrageio para garantir comida e abrigo, possuindo, do mesmo modo, apropriada coesão grupal, período do longo processo evolutivo ocorrido na espécie humana, fenômeno biocultural ainda vivenciado nos dias de hoje. Sobre o tópico, Dunbar et al (2003) afirmam que "human languages, such as French, Cantonese or American Sign Language, are socio-cultural entities, languages are maintained and transmitted by acts for speaking and writing; and this is also the means by with languages evolve" (Dunbar et al 1999: 173; Lewin 1999).

O sentido de evolução o qual asseguram Dunbar et al (2003) está relacionado às ocasiões de transmissão e transformação rotineiras das línguas humanas, que envolvem ainda o sentido de cooperativismo e aliança entre os grupos do passado - e do presente! Logo, pode-se dizer que toda linguagem humana é dinâmica e garante às comunidades linguísticas a formação de identidade e colaboração:

Is the case in hunter-gatherer societies that reciprocity is more intense within the linguistic group than outside it. The !Kung San, for example form a system of sharing and exchange $[\ldots]$.However, this community only extends up to the ethnolinguistic boundary. [...] Within tribes [!Kung San], generosity and largesse are prized ${ }^{3}$ (Dunbar et al 2003: 222-223). 
Apesar de estudos como de Dunbar et al (2003) que elaboraram a teoria da evolução cultural em vários aspectos, como a língua, a organização social, a arte, os rituais, a música, etc., o consenso social enfrenta modificações não apenas nos entrelaçamentos mais conexos da cultura humana, mas também nas manifestações políticas e econômicas de inúmeras sociedades. Muitos povos e nações no mundo inteiro construíram diferenças abruptas, como foi o advento da linguagem, que sustentam a variabilidade de sentidos, conotações, morfologias, usos e significados que podem ser usados para criar rótulos que originam preconceitos ao invés de cooperativismo, como antes foi conceituado pelos autores. Hoje a linguagem também é usada para impor diferenças e hierarquias, transmitindo diversos significados valorativos, nem sempre apaziguadores (Dunbar et al 1999; Calvet 2002; Website 2013).

As variáveis linguísticas e variáveis sociais permitem elementos de alterações constantes, porque "as línguas mudam todos os dias, evoluem, mas a essa mudança diacrônica se acrescenta outra, a sincrônica: pode-se perceber numa língua, continuamente, a coexistência de formas diferentes de um mesmo significado" (Calvet 2002: 79). Como exemplo, Calvet (2002) descreve o "Vernáculo Negro-Americano", citando Labov":

Labov vai trabalhar com crianças em "guetos urbanos" e esclarece que "quanto à população que nos interessa, ela se compõe de membros pertencentes por completo à cultura vernacular das ruas, rejeita- das pelo sistema escolar", e assim ele será levado a considerar o que chama de "vernáculo negro-americano", que possui suas próprias regras e apresenta tão grande número de formas "não padrão" que é inútil querer descrevê-los em termos de desvios de norma (Calvet 2002: 87-88).

O que Calvet (2002: 87) apresenta apud Labov são as formas de locução de moradores do bairro do Harlem, em Nova Iorque, EUA, alegando que "O falar dos jovens negros parte de um problema eminentemente prático: estudar as causas de seu fracasso escolar, em particular, de suas dificuldades de aprendizado da leitura". Todavia, tais déficits estão atrelados a questões culturais, como o acesso às melhores escolas e o racismo norte-americano, que até a contemporaneidade é uma realidade naquele país, significando que a utilização da variável da Língua Inglesa demarca diferenças sociorraciais contundentes, fazendo da língua um instrumento de coerção.

Nesse sentido, de fronteiras diferenciais entre grupos específicos, a experiência de ter uma doença e conviver com situações-limite de desrespeito e indignidade por atitudes inflexíveis, proporcionam um modo pejorativo à classificação dos sujeitos, como os apelidos criados para coagir e categorizar as pessoas, que contribuem para a ausência de nexo de um grupo. Para os indivíduos que vivenciam enfermidades complexas, como as doenças que causam estigmas (Hanseníase, HIV, Psoríase, etc.) e, principalmente, aquelas de origem genética (DF, Fibrose Cística, 
Mucopolissacaridoses, Síndrome de Down, entre outras), são circunstâncias de conjuntura social que exigem o reconhecimento de demandas que englobem um problema de saúde pública determinante na avaliação da qualidade de vida desses segmentos, precisamente por compreender a saúde além de um bem-estar físico e mental, mas, sobretudo, biossocial e humano.

Igualmente, considerar uma pessoa como "doente, "fraca" ou "coitada" por causa de sua condição de saúde, quer seja hereditária, complexa ou biológica é uma atitude constante que as pessoas com DF no Estado do Pará escutam e enfrentam em seu cotidiano biossocial $^{5}$, devido conviver com os imponderáveis de uma doença, que sob a pecha de variados codinomes ou desfeitas que os indivíduos costumam lidar em sua vivência e, muitas vezes, tentam suplantar tal situação de completo incômodo, são circunstâncias que devem ser consideradas de maneira particularizada e, por isso, a razão primeira da ponderação que segue.

\section{Referenciais e Discussão}

Para Calvet (2002: 58, grifo meu): "A história está repleta de provérbios ou de fórmulas pré-fabricadas que explicam os preconceitos de cada época contra as línguas". O contexto da língua articulada está atrelado, necessariamente, ao "bem falar" ou as locuções que causam constrangimentos as comunidades linguísticas, como é o episódio da frase: "Parler français comme une vache espagnole", cuja origem ("comme un Basque espagnol") nos mostra que o juízo de valor sobre a lín- gua atinge outro alvo, o falante" (Calvet 2002: 59). Tais orações demonstram que existe uma escala de valores que são expressas por meio da variação linguística, sendo que "o que interessa à sociolinguística é o comportamento social que essa norma pode provocar", na qual os falantes podem contribuir para a supervalorização da própria língua em detrimento de outra diferente (Calvet 2002: 60).

Calvet (2002) comunica ainda que existem situações de segurança e insegurança, assim como atitudes positivas e negativas em torno de uma língua ou variação linguística, onde algumas ideias podem levar à classificação de "pronúncias feias ou vulgares", mas sempre relatando ações a respeito de normas cultas ou padrões das línguas, classificando estilos ou conotações de falas que podem compilar uma "diferença social" ou mesmo a "relação de forças" entre os praticantes de uma língua, não obstante, utilizo o autor neste texto para denominar outras formas de "poder" quando certo falante de determinada língua, nesse caso, a Língua Portuguesa, apropria-se de alcunhas ou declarações da própria língua para causar embaraço, incerteza, constrangimento e demarcar lugares que diferem aquele sujeito de outros que compõem o restante da sociedade.

A respeito do assunto da subordinação pelo poder de uma língua, em se tratando de pessoas com DF, o linguajar é utilizado como um instrumento de coação ou exclusão social, para estigmatizar sujeitos que lidam com os percalços de uma doença de difícil tratamento e ainda são submetidos a 
estereótipos como: “amarelão”, “amarelo" ou "olho amarelo" para designar alguém com icterícia devido complicações da própria doença, porém sem esquecer que esta condição não é específica da DF e também estará presente em muitas outras manifestações clínicas. Bagno revela na matéria sobre "Variação linguística: preconceito linguístico", no site "Pedagogia ao pé da letra" (Website 2013), que "os apelidos pejorativos são inaceitáveis, quando dizem respeito aos falantes de sua língua materna: é preciso encontrar o ponto de equilíbrio entre a adequabilidade e a aceitabilidade, tudo vai depender da situação de uso da língua em que nos encontramos" (Website 2013: 01).

Segundo Bourdieu (2008), o julgamento social de uma pessoa ou um grupo, deve ser avaliado partindo das características estruturais e universais de dada sociedade. O sociólogo concebe que no, "sentido da distinção" (do gosto, do estilo de vida, da discriminação), a estrutura social também está presente no discurso de quem fala, podendo ser compreendida como uma "linguagem política”, como segue:

A indeterminação essencial da relação entre experiência e expressão é acompanhada pelo efeito de imposição de legitimidade e de censura, exercido pelo uso dominante da linguagem, tacitamente reconhecido, até mesmo, pelos porta-vozes dos dominados, como modo de expressão legítimo da opinião pública (Bourdieu 2008: 431).

$\mathrm{Na}$ consequente observação, Bourdieu (2008: 431, adendo) garante também que "a linguagem dominante destrói, desacreditando-o [o sujeito], sendo o discurso político espontâneo dos dominados". O autor cientifica, além disso, que:

A linguagem deteriorada em que as "palavras difíceis" são utilizadas simplesmente para marcar a dignidade da intenção expressiva - e que, incapaz de transmitir algo de verdadeiro, real ou "sentido", desapossa seu utilizador da própria experiência que, segundo se presume, tal linguagem deveria exprimir (Bourdieu 2008: 431).

Em outras palavras, o francês analisa as demandas da desigualdade e da exclusão mediante as circunstâncias da estrutura social da coletividade a qual faz parte, constatando que as expressões e os discursos da linguagem, assim como as relações econômicas, artísticas e de estilo de vida, compõem um habitus que designa o status quo dos sujeitos que fazem parte de alianças socialmente construídas por essa relações, quais sejam: as hierarquias socioeconômicas, de vontades (gostos), de classe (especialmente a Classe Média ou a Pequena Burguesia) ou de poder simbólico, considerando a linguagem dominante da burguesia francesa como "uma linguagem estéril, como se fosse uma espécie de máquina automática que produz seus rosários de fórmulas canônicas e de palavras de ordem, além de desapossar, pela segunda vez, os mandantes de sua experiência" (Bourdieu 2008: 431).

Em consideração às ações econômicas da língua, Calvet (2002) também cita Bourdieu ao refletir sobre os "mercados linguísticos”, assumindo que: 
[Bourdieu] parte da constatação de que a linguística pós-saussuriana se construiu sobre a rejeição do caráter social da língua e que "os linguistas não têm escolha senão buscar desesperadamente na língua o que está inscrito nas relações sociais onde ela funciona" [...]. O discurso não é apenas uma mensagem, é também um produto. (Calvet 2002: 58 , grifo).

Calvet (2002) continua citando Bourdier na seguinte passagem:

O discurso não é apenas uma mensagem destinada a ser decifrada; é também um produto que entregamos à apreciação dos outros, cujo valor se definirá na relação com outros produtos mais raros ou mais comuns. O efeito do mercado linguístico $[. .$.$] não para de exercer até$ nas trocas mais comuns da existência cotidiana [...]. Instrumento de comunicação, a língua é também sinal exterior de riqueza (Calvet 2002 apud Bourdieu 19907: 94-95, grifos do autor).

Em conclusão, Calvet (2002: 95) assegura que, para Bourdieu, "além da simples comunicação, os discursos são signos de riqueza, signos de autoridade, eles são emitidos para ser avaliados e obedecidos e que a estrutura social está presente no discurso". Dessa forma, avaliar o domínio que a língua desempenha sobre as pessoas é uma maneira plausível de considerar os efeitos que ofensas e desqualificações exercem sobre os indivíduos falantes de sua própria língua, indicados como pertencentes à mesma comunidade linguística.

Para compreender o cotidiano biológico e social de interlocutores com DF,
Silva (2015) garante que:

A sensação de medo e incerteza por conviver com os sintomas, os estigmas étnicorraciais, as dificuldades de acessibilidade ao tratamento de saúde, as restrições estruturais por consequência do adoecimento, assim como a busca por mecanismos complementares de tratamentos não acadêmicos configuram os indicativos das relações biossociais da DF no Pará (Silva 2015: 120).

Entre o medo e a incerteza apontados por Silva (2015), a questão mais decisiva a ser considerada são as maneiras desconfortáveis como 57\% dos interlocutores evidenciaram ao garantir que sofreram ou sofrem preconceito e discriminação por ter uma doença como a DF, tanto sociorracial e institucional, como devido a um comportamento que se aproxima do "bullying" motivado pelos efeitos fisiológicos trazidos pelo agravo ${ }^{1}$.

Um tema fundamental na DF está relacionado ao racismo ${ }^{9}$ versus saúde em nossa sociedade, fenômeno bastante discutido por ser considerado um dos causadores da desigualdade da qualidade de vida entre grupos sociorraciais diferentes. A DF teve sua provável origem no Continente Africano, onde ocorreu um aumento de sua frequência, possivelmente em resposta a fatores seletivos. Portanto, espera-se que sua frequência seja mais elevada em pessoas que apresentam uma origem africana. Por outro lado, em países miscigenados como o Brasil, o processo de adoecimento acomete vários grupos populacionais com maior ou menor contribuição africana, sendo um 
dos indicadores de saúde dessas populações (ALAI 2010; Brasil 2007b; Cordeiro e Ferreira 2009; Munanga 2003; Brasil 2001; Naoum 2000b). Cordeiro e Ferreira (2009) retratam o assunto da seguinte maneira:

As modalidades pelas quais a discriminação se expressa na área de saúde nunca são diretas e evidentes, são envolvidas nas teias das relações sociais e econômicas que estruturam e determinam o processo saúde-doença, seja de seus determinantes diretos ou indiretos. É fácil constatar que o acesso aos serviços de saúde varia para os diferentes grupos que compõem a população, com maior desvantagem para os negros, e que os diferentes níveis de reprodução da desigualdade social e de saúde têm suas origens fortemente fincadas no gênero, raça e classe (Cordeiro e Ferreira 2009: 353).

Nos EUA, Jones (2003: 09) julga que "the racism is an important aspect of our social environment that is increasingly being discussed at both national and international levels ${ }^{10}$ '. A iniquidade no tratamento de saúde entre grupos sociorraciais entre os Norte-americanos é assim descrita:

A growing number of scientists hypothesize that racism is a fundamental cause of "racial" and ethnic disparities in health outcomes. Yet the scientific investigation of the role of racism in contributing to health disparities is not simply an academic exercise of establishing a causal relationship or decreasing the amount of unexplained variance in our statistical models. This work will be of value when it identifies the pathways and structural mechanisms by which racism has its impacts. Once that has been accomplished, it will be a matter of political will to target these pathways and mechanisms for intervention $^{11}$ (Jones 2003: 09).

Tanto no Brasil como nos EUA, a demanda do racismo é um pleito de saúde pública, sendo que os apelidos e outras formas de tratamento em relação aos interlocutores com DF são quesitos importantes a discutir, devendo ser considerados como Determinantes Sociais da Saúde (DSS), por comportar elementos sociais, ambientais, de comportamento, (in)segurança e bem-estar de agrupamentos humanos vulneráveis socialmente (Buss e Filho 2007):

Determinantes Sociais da Saúde (DSS) são os fatores sociais, econômicos, culturais, étnicorraciais, psicológicos e comportamentais que influenciam a ocorrência de problemas de saúde e seus fatores de risco na população. [...] são as condições sociais em que as pessoas vivem e trabalham. [...] fatores e mecanismos através dos quais as condições sociais afetam a saúde e que potencialmente podem ser alterados através de ações baseadas em informação (Buss e Filho 2010: 78).

Os DDS são circunstâncias fortemente influenciadas por situações do dia-a-dia no trabalho, na família, na escola e outras conjunções de convivência, sendo que:

O principal desafio dos estudos sobre as relações entre DSS e saúde consiste em estabelecer uma hierarquia de determinações entre os fatores mais gerais de natureza so- 
cial, econômica, política e as mediações através das quais esses fatores incidem sobre a situação de saúde de grupos e pessoas (Buss e Filho 2007: 81).

Para considerar o preconceito linguístico como indicativo de DSS, devemos ter em mente que qualquer condição biossocial, psicossocial e ambiental deve ser levada em consideração para avaliar a situação de saúde de pessoas que sofrem preconceitos, especialmente aquelas com uma doença genética como a falciforme.

Em geral, pessoas com DF necessitam, vez por outra, de transfusões sanguíneas (pelo baixo índice de hemoglobina normal no organismo, o que causa anemia e outros sintomas), de forte medicação para dores no corpo (em situações de crises álgicas, principalmente nas articulações, costas e abdômen), são mais sensíveis a banhos de igarapé, sol, chuva, rio ou piscina, porque mudanças bruscas de temperaturas podem desencadear uma crise de dor, ou desenvolvem outras doenças oportunistas como a esplenomegalia (inchaço desordenado do baço por causa do sequestro esplênico, que é uma forma anormal do funcionamento daquele órgão), a icterícia (hiperbilirrubinemia no sangue, produção acelerada de uma substância amarela da bile, que causa o amarelamento da pele e dos globos oculares), a síndrome mão-pé (inchaço das articulações das mãos e dos pés, especialmente em crianças de colo), o Acidente Vascular Cerebral (devido complicações no processo circulatório por ocasião da falcização das hemácias, que causam vaso-oclusão e o posterior
AVC - a falcização é também a causa de dores e diferentes fatores de risco), entre outros sintomas e consequências que conformam o dia-a-dia de indivíduos com a DF, normalmente nas formas intermediárias e graves da doença (Silva e Silva 2013; Brasil 2007a; Naoum 2000a, Naoum et al 1997).

Como podemos observar o universo biossocial dos interlocutores com DF é complexo e, em decorrência do adoecimento, trazem no corpo as consequências originadas pelas complicações da doença, que por desinformação, tanto de pessoas da família, como no trabalho, nos serviços de saúde e demais espaços de sociabilidades e interação comunicativa, são nomeados como sujeitos adoentados, como expõem em suas falas a seguir (Silva e Silva 2013; Guedes e Diniz 2007; Naoum e Bonini-Domingues 2007; Website Rede Saci 2003; Silva et al 1993).

\section{Pessoas com Doença Falciforme e Rela- tos de Insultos Verbais na Língua Por- tuguesa}

Quando sugerimos as peculiaridades de insultos verbais vivenciados por homens e mulheres com DF, a teoria descrita por Bourdieu (2008) de que a estrutura social faz parte do discurso, pode ser considerada na prática e isso se deve ao fato de a sociedade comportar conjunturas sociais que delineiam como, porquê e onde os sujeitos que convivem com a doença passam a lidar com situações avessas à sua saúde.

A língua enquanto um fato social pode originar identidade, empatia e inclusão dentro de uma coletividade, ao mesmo 
tempo em que pode causar exclusão e preconceito no seu grupo ou em outro agrupamento, exatamente por condicionar elementos verbais que acompanham os processos de conflito. Por conseguinte, adotando a ideia de Bourdieu (2008), as línguas variam de acordo com os interesses das classes sociais. Entretanto, acrescentaria que o uso da língua muda de acordo com o sentido dado a ela para exaltar ou desestruturar uma pessoa ou um grupo, dependendo de sua abordagem (Bourdieu 2008; Durkheim 2001; Calvet 2002). Para os interlocutores com DF, enfrentar o preconceito de expressões pejorativas dos falantes da Língua Portuguesa, isto é, de sua própria língua, é um desafio diário a ser enfrentado, pois se sentem excluídos socialmente pelo simples fato de ter uma doença genética, a qual muitas pessoas desconhecem. Os relatos a seguir demonstram como ocorre a dimensão do problema:

Ele sofre preconceito sim, na escola, por causa da fisionomia dele, os olhos dele, a pele dele... O comportamento dele é diferente das pessoas normais, eles não fazem arte por causa da doença, ele sofre discriminação porque chamam ele de "olho amarelo", "pele amarela", ele fica aborrecido, mas fica na dele, calado, na convivência na rua não há discriminação. Nunca pensei em perguntar com a professora sobre certas atitudes por lá (Irmã e cuidadora de adolescente de 17 anos com DF, Nordeste do Estado do Pará).

Muitas piadinhas que a gente recebe, porque eu tinha uma úlcera que era na perna, me discriminavam muito. No tempo que eu tinha me chamavam de "perna podre", eu levava na esportiva, a ferida continua aberta, mas tá melhor agora [ele se emociona, mas sorri depois] (Luís, 33 anos, Desempregado, Belém).

Por causa da anemia falciforme o olho fica amarelo, ficam apelidando de "amarelão", de "amarelo". Eu não faço nada, não ia adiantar... (Adriano, Estudante, 19 anos, Região Nordeste do Pará).

Tornam-se evidentes nas falas que os insultos verbais usados são formas discriminatórias de uso de expressões depreciativas em relação à aparência ou sequelas dos indivíduos, pois muitas vezes os profissionais da educação e até mesmo da área da saúde desconhecem as caraterísticas da DF, utilizando-se de palavras mal-intencionadas para menosprezar as pessoas, desinformação que causa enorme desconforto em sua condição emocional. Segundo Silva (2012):

Além da susceptibilidade em si, a terapêutica dos sujeitos deve ser vinculada a processos de comprometimento de orientações e informações sobre a DF a pessoas que se encontram longe dos centros urbanos, pois alguns profissionais de saúde desatualizados, muitas vezes, desconhecem a enfermidade (Silva 2012: 59).

Silva (2012: 84) adverte que "no seu dia-a-dia, os interlocutores com DF no Pará frequentemente sofrem com estereótipos, sendo desqualificados em diversos estágios da vida e estigmatizados com apelidos", situação que complica ainda mais o cotidiano desses indivíduos, noticiando também que: 
Indivíduos que se encontram "de fora" da experiência de viver com $\mathrm{DF}$, pessoas com quem os interlocutores mantem sociabilidades, costumam classificar o Corpo dos informantes como "doente", quando na verdade a fragilidade da doença nem sempre é reconhecida pelos sujeitos. Isso reforça a ausência ou precariedade de informações sobre DF que a sociedade reflete (Silva 2012: 97).

É fato que o desconhecimento sobre a DF pode agravar a situação de saúde dos sujeitos, justamente porque "a desinformação é tão generalizada que quando esse tipo de doença passou a ser detectado pelo teste do pezinho, causava peregrinação de pais a hospitais e consultórios em busca de resposta para os sintomas que o filho apresentava" (Website Rede Saci² 2003: 01). A falta de elucidação a respeito da doença trás má impressão sobre as pessoas com DF, indicando o porquê do processo, considerada uma ocasião embaraçosa pelo grupo:

As pessoas quando sabem do meu quadro clínico, das complicações que posso ter, geralmente ficam com sentimento de pena: "Ah coitadinha!", e em muitos casos acabam subestimando o meu potencial, embora isso tenha mudado ultimamente, principalmente depois da aprovação no mestrado, o que não é grande coisa, mas enfim... Certa vez uma garota me perguntou o que realmente eu tinha e, após eu explicar, ela questionou se era uma "doença contagiosa". De forma rotineira, sempre tem algum comentário indesejado referente à palidez e etc. (Rita de Cássia, Bol- sista, 25 anos, Zona do Salgado, Nordeste Paraense).

Já sofri preconceito porque o pessoal pensa que pega, porque o pessoal pensa que é "transmissível", eles morrem de medo. [Pergunto: "Que pessoal?"] O pessoal que mora na minha cidade. Só os meus amigos mais íntimos que sabem, eu não gosto de comentar. Eu choro porque tenho medo de morrer. (Ivone, 37 anos, Merendeira, Sul do Pará).

Sofri preconceito há muito tempo atrás quando era adolescente. É porque existe uma grande falta de informação, mas nada que não seja explicado (Rui, Servidor Público, 26 anos, Belém).

O insulto a uma pessoa fragilizada por uma doença é um indício para o enredamento de sua fragilidade, objeto de artigos e debates em torno da vulnerabilidade da DF, contudo, grande parte das pessoas que convivem com o episódio, geralmente, costumam lidar com o problema de modo a se isolar socialmente, causando nelas um transtorno psicossocial (Silva 2013; Buss e Filho 2007; De Marco 2006; Batista 2008; Naoum 2000a). Abaixo os interlocutores discorrem sobre o seu estado psicossocial:

Eu tenho medo realmente do preconceito, eu prefiro nem falar porque eu acabei ficando muito calada (Rosa, Técnica em Agroindústria, 30 anos, Interior do Estado do Pará).

Ele deixou de frequentar a sala especial porque os meninos diziam que ele era doido. A única coisa que ele tem é uma grande dificuldade de aprender, é uma dificuldade imensa 
pra aprender, já pagamos até Prof. ${ }^{a}$ particular, mas ele não consegue aprender (Benvinda, Aposentada, Avó de Adolescente de 14 anos com DF, Belém).

Já sofri preconceito, primeiro das meninas da minha idade, me chamavam de "amarela", um monte de apelido, eu chorava [a informante começa a chorar]. A gente era criança. Hoje muitas pessoas ainda falam, em casa, com meus irmãos, brigas com minhas irmãs, elas me xingam (Sheila, Estudante, 29 anos, Zona Rural do Estado do Pará).

É mais psicológico, tenho uma relação muito complicada com a mamãe, então eu não quero ter um filho e tratar ele do jeito que a mamãe fez, comigo é na base da briga, ela me culpa por todas as suas frustrações, como se eu tivesse tirado a liberdade dela, então nada do que eu faço presta, nada tá bom. Quando eu era criança, minha letra não era bonita, só a letra de fulana (Vanuza, Biblioteconomista, 29 anos, Espírito Santo).

Para Carvalho e Melo (2014: 627), "no campo da linguística, o insulto encontra-se relacionado, de maneira geral, a uma forma de emprego de linguagem torpe, também chamada de disfêmica". As autoras afirmam ainda que "O insulto é o avesso da linguagem polida ligada à cortesia e, portanto, à civilidade". De tal modo, o insulto verbal é considerado como uma "violência estrutural e suplementar", que inibe o sujeito ultrajado a vivenciar uma violência instituída pelo uso de uma linguagem de injúria, prejudicando a dignidade da pessoa:
Realçamos que o insulto [...], afasta-se da concepção linguística e se aproxima do tipo de violência suplementar presente na contemporaneidade, desfazendo os efeitos simbólicos produzidos pela violência estrutural, ou seja, desfazendo os limites instituídos pela palavra, o vazio que ela comporta, ou melhor, dissolvendo a palavra (Cardoso e Melo 2014: 629).

Cardoso e Melo (2014: 628) perguntam: "Que violência queremos discutir?”. Pode-se concluir que a agressão causada pelo insulto é uma violência simbólica, estruturante, de classe, sociorracial e, sobretudo, desumana. Desse modo, a língua usada como insulto verbal pode, sobremaneira, alterar a condição de bem-estar dos sujeitos, como notamos nos depoimentos seguintes:

Todo mundo fala de "esqueleto" [a entrevistada começa a chorar], porque eu sou pálida, foi na escola, eu parei de estudar por causa disso, quando chegava em casa, falava com a mamãe para que reclamasse na Diretoria, mas as zombarias permaneceram (Roseane, Estudante de Supletivo, 20 anos, Belém).

Tem dias que eu faço de tudo, outros eu fico deitada. Quando eu namorei um rapaz, a mãe dele disse que não queria que o filho dela namorava com uma pessoa doente, não servia pro filho dela porque eu era doente, ela me chamava de "morcego", de "vampiro" [fica emocionada, chateada, faz uma expressão triste]. As pessoas que eu conheço me chamam assim, mas eu não ligo mais, porque as pessoas são ignorantes. Agora eles pararam mais, porque eu disse pra eles que 
isso pode acontecer com qualquer pessoa, ai eles pararam mais de me chamar assim (Élida, Do lar, 25 anos, Marabá).

Outra abordagem essencial a ser ponderada diz respeito ao que se convencionou chamar de "Racismo Institucional", conceituado pelo Geledés (2013):

O racismo institucional, também denominado racismo sistêmico, como mecanismo estrutural que garante a exclusão seletiva dos grupos racialmente subordinados - negros/as, indígenas, ciganos/as, para citar a realidade latino-americana e brasileira da diáspora africana - atuando como alavanca importante da exclusão diferenciada de diferentes sujeitos nestes grupos. O racismo institucional ou sistêmico opera de forma a induzir, manter e condicionar a organização e a ação do Estado, suas instituições e políticas públicas - atuando também nas instituições privadas, produzindo e reproduzindo a hierarquia racial (Geledés 2013: 17).

O racismo institucional (Geledés 2013: 31) é um "mecanismo produtivo, capaz de gerar e retroalimentar a exclusão racial, muito mais do que um suposto efeito colateral ou inercial da ideologia", ou seja, uma maneira sutil de exclusão sociorracial. Nesse caso, os insultos verbais são formas de configurar essa realidade. A via de preconceito e discriminação é dupla, por envolver o racismo propriamente dito conjuntamente com o racismo institucional. Os relatos subsequentes demonstram onde essas situações ocorrem:

Sofri discriminação na escola, no trabalho, em casa, na igreja, no atendimento a saúde. As pessoas tratavam-me como doente [trabalho, família, igreja], já na escola as pessoas pensavam que eu tinha hepatite, doença contagiosa, também colocavam apelidos depreciativos, devido minha baixa estatura. E no que diz respeito ao atendimento a saúde os profissionais tratavam-me como se fosse uma "viciada em drogas", devido precisar fazer uso dos opióides, medicamentos controlados, que apesar de já ser padronizados pelo Ministério da Saúde para uso em crises dolorosas provocadas pela anemia falciforme, não é do conhecimento de muitos profissionais, devido falta de campanhas educativas (Joana, Pedagoga, 35 anos, Belém).

$\mathrm{Na}$ escola ficam me chamando de "* bracinho" [ ${ }^{*}$ primeiro nome dele], por causa do meu AVC, de vampirinho, até aqui no Hemopa eles me chamam de vampirinho, eu não gosto [O adolescente começou a chorar muito] (Leonardo, Ensino Médio Incompleto, 16 anos, Região Sudeste do Pará).

$\mathrm{Na}$ verdade eu já tinha pego um material falando como ele deveria ser tratado. $\mathrm{Na}$ escola, a merendeira serviu Nescau com bolacha, ele pediu mais e ela disse que o bucho dele era grande, só porque ele pediu bolacha. Ele me contou e eu fiquei chateada. Um dia eu levei o material de anemia falciforme pra diretora da escola pra que isso não ocorresse mais, após eu ter denunciado a merendeira, ela tratou ele normal (Professora, Mãe de Criança de 08 anos com DF, Breu Branco).

É imprescindível ressaltar que qualquer insulto verbal ou preconceito por 
causa de uma doença crônica, devem ser considerados como estigmas que podem acentuar a situação de saúde de sujeitos que sofrem tais ocorrências, marcando condições de desigualdades latentes. Em outra linha, ao estudar os efeitos do estigma entre pessoas com HIV, Parker (2013) argumenta que:

O estigma deve ser compreendido mais claramente como ligado ao funcionamento das 'desigualdades sociais'; isso significa dizer que as questões de estigmatização e discriminação, quer em relação ao HIV e à Aids ou a qualquer outra questão, exige que reflitamos mais amplamente sobre a forma que alguns indivíduos e grupos passam a ser socialmente excluídos e sobre as forças que criam e reforçam a exclusão em diferentes contextos (Parker 2013: 29, grifo meu).

Em assim sendo, considerar a força de uma língua, seja para agregar ou afastar os seus falantes, deve ser uma crítica aprofundada a ponto de não servir como instrumento de marca social e, enfim:

[...] nos engajarmos nas batalhas que acabarão sendo necessárias para transformar as estruturas e processos que produzem e reproduzem o estigma, o preconceito e a discriminação entre os maiores inimigos da saúde e do bem-estar no mundo contemporâneo (Parker 2013: 44).

As declarações que seguem enfatizam situações cotidianas de estigma entre as pessoas com DF em diferentes cidades do Brasil:

O bom profissional [da escola onde ela trabalhava] entendia, mas tem profissional [a diretora da escola] que a partir do momento quem tu começas a faltar, eu comecei a perceber que eles me rotulavam [os outros professores e funcionários da escola], até que me afastei da função de docência. A vice-diretora disse que eu inventava doença pra eu não trabalhar (Rosa, 49 anos, Pedagoga, Belém).

Não é sempre, mas já passei por algumas situações chatas, por exemplo, em uma entrevista de emprego fui perguntada sobre uma cicatriz que tenho no pescoço, então expliquei que foi devido a uma crise da anemia. A pessoa nem sabia do que se tratava e já foi me dispensando (Virgínia, 25 anos, Jornalista, São Gonçalo/RJ, Rede Privada de Saúde).

$\mathrm{Na}$ rua eu encontrei com uma tia que me disse: “Tu não vai arranjar emprego em lugar nenhum por causa dessa tua doença"' [emociona-se ligeiramente]. A minha ex-patroa disse que eu estava dando prejuízo pra ela, que eu só vive doente, disse que eu não quero trabalhar, então eu pedi que ela me demitisse e ela me demitiu (José, Ribeirinho/Desempregado, 21 anos, Mesorregião do Marajó).

O rótulo é um estigma muito presente entre pessoas com DF, fato que desestrutura o dia-a-dia dos interlocutores e que deve ser analisado seriamente por toda a sociedade. Como vimos, muitos são os exemplos envolvendo insultos verbais como apelidos e acintes que as pessoas com DF - tanto crianças, como adolescentes e adultos - recebem declarações preconceituosas por ter a doença e suas consequentes sequelas. Na maioria das vezes, o pro- 
blema ocorre devido à desinformação sobre o agravo ou negligência das instituições de saúde e do Estado em tratar o assunto como questão de saúde pública a ser enfrentado no cotidiano desses espaços de saúde e sociabilidades.

\section{CONSIDERAÇÕES FINAIS}

Qualificar o comportamento de falantes de uma língua em relação a seu modo de discurso é uma tarefa complexa, entretanto, analisar os desvios, os preconceitos linguísticos, os insultos verbais e as relações de poder dentro de uma língua são argumentos que podem ser arrolados como conexos, principalmente quando pessoas que sofrem racismo, racismo institucional, preconceito sociorracial e estigmas por sua aparência ou cor, chamam a atenção de tais circunstâncias em seu cotidiano biossocial, isto é, indivíduos com uma doença genética ou qualquer outro agravo crônico.

Em particular, para os interlocutores com DF, a desqualificação de sua pessoa por sua aparência ou doença e, consequentemente, de seu estado de saúde com apelidos, insultos e indignidade social devido conviver com uma enfermidade, são ocorrências de difícil convivência, pois enfrentar as sequelas fisiológicas da própria doença com dores, internações hospitalares e transfusões de sangue ao longo da vida e, além disso, ouvir expressões que ferem a sua dignidade são fatores que prejudicam sobremaneira a sua então fragilizada qualidade de vida, tornando o indivíduo ainda mais vulnerável por sua condição genética, portanto, um Determinante Social em Saúde que deve ser evitado.

Rotular qualquer indivíduo por ter problemas de saúde recorrentes é uma atitude violenta em vários sentidos: simbólica, de classe, econômica, sociorracial e de poder, que a incompreensão do agravo biológico vivenciado por um grupo ou um indivíduo, é um quadro social que deve ser alterado. Todavia, a mudança de comportamento é uma ação em longo prazo, que deve ser iniciada nos próprios serviços de saúde pública ou privada, com informações em saúde e educação continuada, concomitantemente ampliando para outros lócus de convivências, como a escola, o local de trabalho, a família, etc., a fim de estabelecer novas vicissitudes linguísticas e reciprocidades humanas, no sentido de promover a saúde e a melhor qualidade de vida de pessoas com DF, efetivando políticas públicas constantes em prol de dirimir a vulnerabilidade desse segmento populacional no Estado do Pará e no Brasil como um todo.

\section{NOTAS}

${ }^{1} \mathrm{O}$ bullying não é instrumento de análise no texto, contudo, é importante ressaltar que os interlocutores em questão também enfrentam situações dessa categoria.

${ }^{1}$ Segundo Brasil (2002: 06): "A doença falciforme é uma alteração genética, caracterizada por um tipo de hemoglobina anormal designada por hemoglobina $S$ (ou Hb S) que provoca a distorção dos eritrócitos, fazendo-os tomar a forma de "foice" ou "meia-lua". O termo doença falciforme define as hemoglo- 
binopatias nas quais pelo menos uma das hemoglobinas anormais é a $H b S$. As doenças falciformes mais frequentes são a Anemia Falciforme (ou Hb SS ), a $S$ Talassemia on Microdrepanocitose e as duplas heterozigoses $\mathrm{Hb}$ SC e Hb SD.

${ }^{2}$ A Rede Saci é um projeto do Programa USP Legal que "atua como facilitadora da comunicação e da difusão de informações sobre deficiência, visando a estimular a inclusão social e digital, a melhoria da qualidade de vida e o exercício da cidadania das pessoas". Informações no site: http://saci. org.br/. Acesso em 10.Jun.2015.

2 "Linguagens humanas, como o Francês, Cantonês ou a Linguagem de Sinais Americana, são entidades socioculturais. As línguas são mantidas e transmitidas por atos de fala e escrita; e este é também o meio pelo qual as línguas evoluem (Dunbar et al. 1999: 173, tradução livre).

${ }^{3}$ É o caso de sociedades de caçadores-coletores em que a reciprocidade é mais intensa no grupo linguístico do que fora dela. Os Kung San!, por exemplo, formam um sistema de partilha e de troca [...]. No entanto, esta comunidade só se estende até a fronteira etno-linguística [...]. Dentro das tribos [! Kung San], a generosidade e a dádiva são valorizadas (Dunbar et al 1999: 222-223).

${ }^{4}$ William Labov [1927] foi professor de linguística na Universidade da Pensilvânia, hoje aposentado. Desenvolveu pesquisas nas áreas de sociolinguística, variação e mudança linguísticas e dialetologia. Suas obras incluem Padrões Sociolinguísticos. Em outro tema, o autor discute a estratificação social em lojas de departamento de Nova Iorque, como segue no link: http:// web.stanford.edu/class/linguist62n/labov001.pdf.

${ }^{5}$ Sobre o assunto ver o artigo de Silva (2015): “O contexto epidemiológico e biossocial da doença falciforme no Pará,
Amazônia, Brasil"'.

${ }^{6}$ Nas palavras de Calvet (2002: 59): "Falar francês como uma vaca espanhola", cuja origem da segunda frase quer dizer "Como um basco espanhol".

${ }^{7}$ Bourdieu, Pierre. 1990. Ce que parler vent dire. Paris: Fayard, p. 41, citação do autor (Calvet 2002 : 94, nota de rodapé).

${ }^{8}$ Para a American Psychological Association, "Bullying is a form of aggressive behavior in which someone intentionally and repeatedly causes another person injury or discomfort. Bullying can take the form of physical contact, words or more subtle actions. The bullied individual typically has trouble defending him or herself and does nothing to "cause" the bullying." ("Bullying é uma forma de comportamento agressivo em que alguém intencionalmente e repetidamente causa lesão ou desconforto em outra pessoa. Bullying pode assumir a forma de contato físico, palavras ou ações mais sutis. $O$ indivíduo intimidado normalmente tem dificuldade para defender a si mesmo e não faz nada para "causar" o bullying"). Outras informações no site: http://www.apa.org/topics/ bullying/. Acesso em: 06.Jul.2015.

9 "O racismo é uma ideologia que se realiza nas relações entre pessoas e grupos, no desenho e desenvolvimento das políticas públicas, nas estruturas de governo e nas formas de organização dos Estados. Ou seja, trata-se de um fenômeno de abrangência ampla e complexa que penetra e participa da cultura, da política e da ética. [...] Por sua ampla e complexa atuação, o racismo deve ser reconhecido também como um sistema, uma vez que se organiza e se desenvolve através de estruturas, políticas, práticas e normas capazes de definir oportunidades e valores para pessoas e populações a partir de sua aparência atuando em diferentes níveis: pessoal, interpessoal e institucional" (Geledés 2013: 11). 
10 "O racismo é um aspecto importante do nosso ambiente social que está cada vez mais sendo discutido tanto a nível nacional e internacional" (Jones 2003: 09). Disponível em: https://sph.umd.edu/sites/default/files/files/Jones-Confronting-Institutionalized-Racism_Phylon\%202003.pdf. Acesso em: 07.Jul.2015.

11 “Um número crescente de cientistas tem a hipótese de que o racismo é uma causa fundamental das disparidades "raciais" $\mathrm{e}$ étnicas nas condições de saúde. No entanto, a investigação científica do papel do racismo em contribuir com as disparidades de saúde não é simplesmente um exercício acadêmico de estabelecer uma relação causal nesse relacionamento ou diminuindo a quantidade de variância inexplicável no nosso modelo estatístico. Este trabalho terá valor quando identificar os caminhos e mecanismos estruturais pelos quais o racismo tem seus impactos. Uma vez que tenha sido realizado, será uma questão de vontade política para direcionar essas vias e mecanismos para intervenção" (Jones 2003: 09).

\section{REFERÊNCIAS}

ALAI: Agência Afro Latino Euro Americana de Informação. 2010. Notícia: Luiza Bairros torna-se a primeira Ministra de Dilma, in Relatório UFRJ sobre saúde da população negra e o SUS. Disponível em http://alaionline.com/?p=907. Acesso em: 07.Jul.2015.

Batista, T. F. 2008. Con(vivendo) com a anemia falciforme: o olhar da enfermagem para o cotidiano de adolescentes. Dissertação de Mestrado, Programa de Pós Graduação em Enfermagem, Universidade Federal da Bahia, Salvador. 105 p.

Bourdieu, P. 2008. A distinção: crítica social do julgamento. São Paulo: Ed. Souk, EDUSP. 560 p.
Brasil. 2001. Ministério da Saúde. Sistema Nações Unidas. Subsidios para o debate sobre a Política Nacional de Saúde da População Negra: uma questão de equidade. Distrito Federal: Ed. Brasília. 13 p.

Brasil. 2007a. Ministério da Saúde. Biblioteca Virtual em Saúde. Disponível em

http://bvsms.saude.gov.br/. Acesso em 30 Junho.2015.

Brasil. 2007b. Ministério da Saúde. Mapa da prevalência do gene S em algumas regiões do Brasil. Brasília.

Buss, P. M., e A. Pellegrini Filho. 2007. A saúde e seus determinantes sociais. $P H Y$ SIS: Revista de Saúde Coletiva 17(1):77-93.

Calvet, J. L. 2002. Sociolinguística: uma introdução crítica. São Paulo: Parábola. 160 p.

Cordeiro, R. C., e S. L. Ferreira. 2009. Discriminação racial e de gênero em discursos de mulheres negras com anemia falciforme. Revista de Enfermagem Escola Anna Nery 13(2):52-58.

De Marco, M. A. 2006. Do modelo biomédico ao modelo biopsicossocial: um projeto de educação permanente. Revista Brasileira de Educação Médica 30(1):60-72.

Durkheim, E. 2001. As regras do método sociológico. São Paulo: Nacional. 165 p.

Guedes, C., e D. Diniz. 2007. Um caso de discriminação genética: o traço falciforme no

Brasil. PHYSIS: Revista de Saúde Coletiva 17(3):501-520.

Geledés. 2013. Racismo institucional: uma abordagem conceitual. Relatório Geledés - Instituto da Mulher Negra e Cfemea Centro Feminista de Estudos e Assessoria: 01-54.

Hurford, J. 2003. The evolution of language and languages, in The evolution of 
culture: an interdisciplinary view. Edited by R. Dunbar \& C. Power, pp. 173-193. New Jersey: Rutgers University Press, 257 p

Jones, C. P. 2003. Confronting institutionalized racism. Phylon 50(1/2):07-22.

Lewin, R. 1999. Evolução bumana. São Paulo: Atheneu. 526 p.

Munanga, K. 2003. Uma abordagem conceitual das noções de raça, racismo, identidade e etnia. Rio de Janeiro: Texto da Universidade de São Paulo. Palestra proferida no $3^{\circ}$ Seminário Nacional Relações Raciais e Educação-PENESB-RJ. 17 p.

Naoum, P. C., e C. R. Bonini-Domingos. 2007. Dificuldades no diagnóstico laboratorial das hemoglobinopatias. Revista Brasileira de Hematologia e Hemoterapia 29(3):226228. São José do Rio Preto.

Naoum, P. C., A. F. Junior; C. R. BoniniDomingos; W. H. Moreira e R. D. Cançado.

1997. Hemoglobinopatias e talassemias. São Paulo: SARVIER. 171 p.

Naoum, P. C. 2000a. Interferentes eritrocitários e ambientais na anemia falciforme. Revista Brasileira de Hematologia e Hemoterapia 22(1):05-22.

2000b. Prevalência e controle da hemoglobina S. Revista Brasileira de Hematologia e Hemoterapia 22 (Supl. 2): 342-148.

Nettle, D. 2003. Language variation and the evolution of societies, in The evolution of culture: an interdisciplinary view. Edited by R. Dunbar \& C. Power, pp. 214-227. New Jersey: Rutgers University Press, 257 p.

Parker, R. 2013. Interseções entre estigma, preconceito e discriminação na saúde pública mundial, in Estigma e Saúde. Organizado por Monteiro, S. e Villela, V. Rio de Janeiro: Fiocruz. 207 p.

Silva, A. K. 2015. O contexto epidemiológico e biossocial da doença falciforme no
Estado do Pará, Amazônia, Brasil. Revista da ABPN 7(16):103-127.

Silva, A. K. L. S., H. P. Silva. 2013. Anemia falciforme como experiência: Relações entre vulnerabilidade social e corpo doente enquanto fenômeno biocultural no Estado do Pará. Amazônica. Revista de Antropologia (On line) 5(1):10-36.

Silva, A. K. L. S. 2012. Doença como experiência: as relações entre vulnerabilidade social e corpo doente enquanto fenômeno biocultural no Estado do Pará. Dissertação de Mestrado, Programa de Pós Graduação em Antropologia, Universidade Federal do Pará, Belém.

Silva, R. B. P., A. S. Ramalho, e R. M. S. Cassorla,. 1993. A anemia falciforme como problema de saúde pública no Brasil. Revista de Saúde Pública 27(1):54-58.

Silveira Bueno, F. 2007. Minidicionário da Lingua Portuguesa. São Paulo: FTD. P. 20 e 73.

Website Pedagogia do pé da letra. 2015. Matéria com Marcos Bagno: Variação linguística: preconceito linguístico. Disponível em: http://pedagogiaaopedaletra. com/variacao-linguistica-preconceito-linguistico/. Acesso em: 05.Jul.2015.

Website Rede Saci. 2003. Matéria com Berta Marchiori: Desinformação "agrava" doença falciforme. Disponível em: http:/ / saci.org.br/? modulo=akemi\&paramet ro $=6428$. Acesso em 08.Jul.2015.otas

Recebido em 09/01/2017

Aprovado em 05/02/2017 